\title{
SIMULASI PENGENDALIAN KECEPATAN PUTAR CEILING FAN BERBASIS ARDUINO
}

\author{
I Gede Suputra Widharma ${ }^{1}$, I Nengah Sunaya ${ }^{2}$, Mardiki Supriadi ${ }^{3}$ \\ ${ }^{1}$ Program Studi Teknik Otomasi, JurusanTeknik Elektro, Politeknik Negeri Bali \\ Kampus Bukit Jimbaran, Kuta, Badung, Bali \\ ${ }^{2}$ Program Studi Teknik Listrik, JurusanTeknik Elektro, Politeknik Negeri Bali \\ Kampus Bukit Jimbaran, Kuta, Badung, Bali \\ ${ }^{3}$ Fakultas Teknik, Prodi Teknik Industri, Universitas Mahendradatta \\ Kampus Pusat Peguyangan, Badung, Bali \\ Email: suputra.widharma@gmail.com,nsunaya@pnb.ac.id,mardikisupriadi@gmail.com
}

\begin{abstract}
Abstrak - Simulasi pengendalian kecepatan putar ceiling fan ini berbasiskan pada system mikrokontroller arduino sebagai pusat kendalinya, dan dua buah fototransistor sebagai sensor, serta komponen-komponen pendukung lainnya.Sensor cahaya yang berupa fototransistor, bekerja berdasarkan adanya perbedaan nilai tahanan antara cahaya yang terpantulkan dan yang tidak terpantulkan, bilamana pada saat fototransistor tidak menangkap cahaya memberikan logika low kepada mikrokontroler, danakan diproses sesuai program yang ada. Kemudian mengaktifkan masing-masing output yang secara bergantian akan mengaktifkan kerja masing-masing relay.

Kegunaan dari simulasi pengendalian kecepatan putar ceiling fan ini adalah mengatur kecepatan putaran ceiling fan secara simultan, sesuai dengan jumlah orang yang berada di dalam suatu ruangan secara otomatis.
\end{abstract}

Kata Kunci : simulasi, kecepatan, putar, ceiling fan, arduino

Abstract - Simulation of round speed controlling to ceiling fan based on arduino microcontroller system as processor centre, and use two fototransistors as sensor, also some electronic components. Light sensors is used fototransistors that work based on different resistance value between light reflected and not reflected. When fototransistor did not get light will be send low level logics to microcontroller and will be processed as program. Then activised each ports of microcontroller and doing one by one simultaneously related how many people in that room automatically.

Keyword: simulation, speed, rounds, ceiling fan, arduino

\section{PENDAHULUAN}

Perkembangan bidang teknologi di Indonesia berlangsung dengan sangat pesat. Demikian juga dengan perkembangan di bidang elektronika. Berbagai jenis peralatan elektronika yang dapat mempermudah pekerjaan manusia semakin canggih. Produk-produk elektronika sudah menjadi suatu kebutuhan yang cukup vital pada masa sekarang ini. Dengan pesatnya kemajuan yang telah dicapai di bidang ini, informasi dan arus komunikasi semakin lancar dan dapat diterima.

Perhatian masyarakat terhadap produk elektronika yang menerapkan sistem control otomatis semakin meningkat. Hal ini disebabkan karena masyarakat menyadari bahwa dengan sistem kendali otomatis, dapat memberikan berbagai keuntungan dan kemudahan. Sesuai dengan perkembangan teknologi dalam bidang elektronika dan komputer, rangkaian control konvensional tadi diganti dengan rangkaian control atau sistem kendali otomatis. Dengan menggunakan sistem kendali otomatis dapat diperoleh beberapa keuntungan diantaranya yaitu: konsumsi daya yang diperlukan pada rangkaian control cukup kecil dan juga pada rangkaian control yang telah jadi dapat dilakukan perubahan maupun pengembangan program sesuai dengan yang diinginkan.

Simulasi pengendali kecepatan putar ceiling fan berbasis mikrokontroller arduino ini dapat mengatur kecepatan putaran ceiling fan secara otomatis. Alat ini bekerja berdasarkan jumlah orang yang ada dalam suatu ruangan, menggunakan dua buah 
sensor yang terhubung ke mikrokontroler, dan output dari mikrokontroler ini akan mengendalikan kecepatan dari ceiling fan, sesuai dengan jumlah orang yang berada di dalam ruangan tersebut.

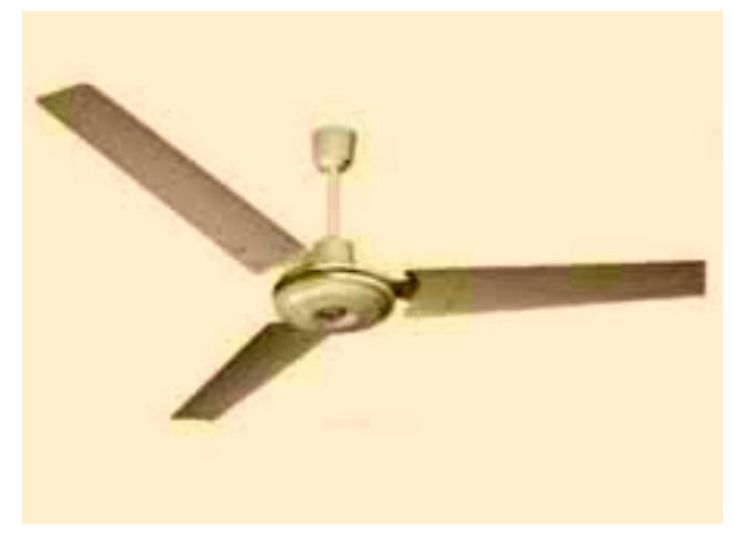

Gambar 1. Bentuk Ceiling Fan

\section{METODOLOGI}

Simulasi pengendalian kecepatan putar ceiling fan berbasis system mikrokontroller arduino ini diujicobakan dalam peralatan ceiling fan di laboratorium.

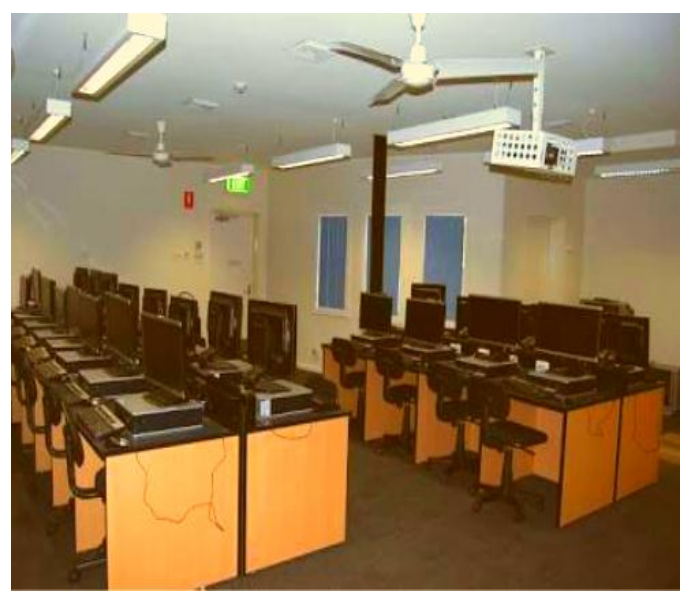

Gambar 2. Ceiling Fan di Laboratorium

\section{HASIL DAN PEMBAHASAN}

\subsection{Perancangan Simulasi}

Simulasi ini terdiri atas tiga bagian utama yaitu bagian input berupa sensor dengan fototransistor, bagian pusat pengendali dengan sistem mikrokontroller, dan bagian output dengan driver motor.

Sistem mikrokontroler keluaran Atmel (AT), dengan 4K byte Flash PEROM (Programabel And Erasable Read Only Memory) yang mempunyai system memori, timer, port serial, dan 32 bit I/O di dalamnya sehingga sangat memungkinkan untuk membentuk suatu sistem yang terdiri dari single chip saja. Perangkat lunak pada Mikrokontroler arduino menggunakan bahasa Assembly yang merupakan program yang ditulis oleh pembuat program berupa kumpulan baris-baris perintah dan biasanya disimpan dengan Ekstension.ASM. Program ini ditulis menggunakan perangkat lunak-perangkat lunak teks editor seperti Notepad atau Editor DOS. Program sumber asembly (assembly source program) merupakan kumpulan dari baris-baris perintah yang ditulis dengan program penyunting teks (text editor) misalnya program EDIT.COM dalam DOS atau program NOTEPAD dalam Windows atau MIDE-51.

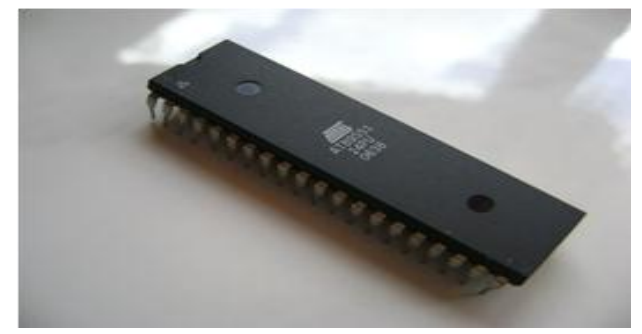

Gambar 3. Mikrokontroller

Komponen elektronika yang menunjang sistem mikrokontroller, yaitu:

- Resistorsebagai pengatur tegangan dan alat pandeteksi sinyal yang mengatur jalannya operasi rangkaian atau bisa juga disebut sebagai penghambat

- Kapasitorsebagai penyimpan muatan listrik sementara dalam medan elektronik.

- Diodamerupakan komponen elektronika yang termasuk komponen aktif. Dioda pada dasarnya dibentuk dari bahan semikonduktor.

- Kristal yang bervibrasi pada frekuensi dari tegangan $A C$ yang dipasang.

- IC Regulator seri 7805 dan 7812 merupakan IC Regulator tegangan dengan tiga terminal.

- Relay terdiri dari kumparan atau selenoida, inti ferromagnetik, dan armatur yang dapat bergerak dan.

- Transformatordigunakan untuk menurunkan tegangan $\mathrm{AC}$. 
- Saklar dapat menghubungkan dan memutuskan arus listrik secara permanent

- Fusesebagai pengaman lebur yang mengamankan rangkaian dari arus hubung singkat dan beban lebih.

Aplikasi system mikrokontroler dalam simulasi pengendali kecepatan putar ceiling fan merupakan perangkat elektronik yang dapat difungsikan untuk mengatur kecepatan yang diperlukan, sesuai dengan jumlah orang yang berada di dalam ruangan.

\section{a) Perencanaan Teknis}

Pada proses pembuatan simulasi ini, perencanaan teknis sangat diperlukan agar pembuatan simulasi tersebut dapat berjalan dengan baik sesuai dengan tujuan yang diharapkan.

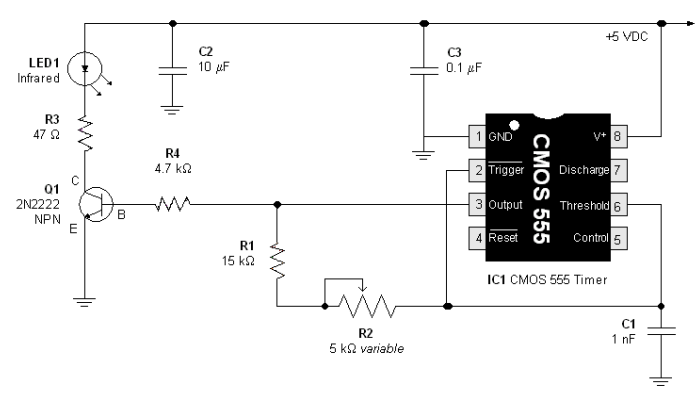

Gambar 4. Rangkaian Sensor

Rangkaian sensor yang akan memberi input pada mikrokontroller.

\section{b) Deskripsi Kerja}

Simulasi Ceiling Fan Speed Controler adalah suatu alat yang bekerja mengatur kecepatan dua buah kipas (Ceiling Fan) melalui sebuah IC Mikrokontroler AT89S51. Dimana pada alat ini terdapat dua buah sensor yang akan mendeteksi objek yang melewatinya. Sensor ini terletak pada pintu, yaitu pada bagian luar dari pintu (sensor A) dan bagian dalam pada pintu (sensor B). Apabila sensor ini menerima sinyal dari objek yang terdeteksi maka sinyal tersebut akan diteruskan ke IC Mikrokontroler.
Masing-masing sensor memiliki fungsi yang berbeda. Sensor A berfungsi sebagai penghitung objek yang akan masuk kedalam ruangan sedangkan sensor $B$ berfungsi sebagai penjumlah objek yang masuk didalam ruangan. Hal ini dimaksudkan agar objek yang masuk kedalam ruangan dibedakan dengan objek yang hanya melewati pintu, sehingga objek yang hanya melewati pintu (terdeteksi sensor A) tetapi tidak masuk kedalam ruangan tidak tercatat sebagai objek yang menempati ruangan.

Oleh karena itu hanya objek yang terdeteksi sebanyak dua kali (melewati sensor A dan sensor B) yang dicatat pada memori IC Mikrokontroler. Sebaliknya, apabila objek menuju keluar ruangan, maka sensor A berfungsi sebagai penjumlah, sedangkan sensor B berfungsi sebagai penghitung. Sehingga objek yang menuju keluar ruangan, yang hanya melewati sensor $B$, tidak tercatat sebagai objek yang keluar dari ruangan, sedangkan objek yang telah melewati sensor $B$ dan sensor $A$, tercatat sebagai objek yang keluar dari ruangan.

c) Proses Pembuatan Alat

Untuk membuat Simulasi pengendali kecepatan putar ceiling fan yang berbasis sistem mikrokontroler ini agar dapat bekerja dengan baik sesuai dengan yang direncanakan maka dalam proses pembuatannya dibagi dalam beberapa tahapan.

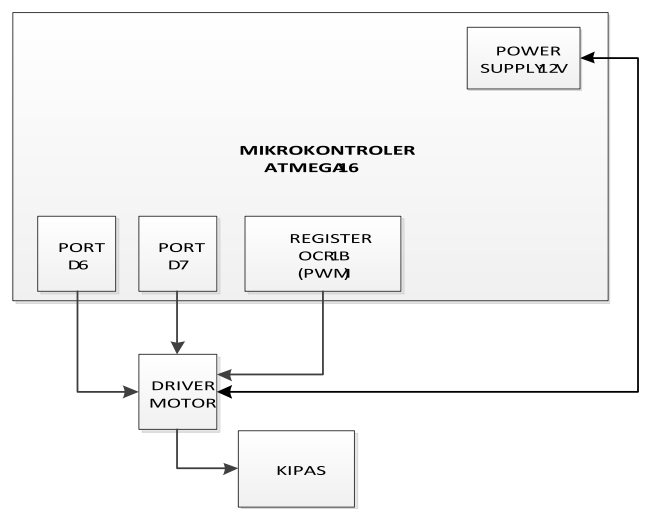

Gambar 5. Blok Diagram Simulasi 


\subsection{Pengujian dan Analisa}

\section{a) Proses Pengujian}

Adapun pengujian dari rangkaian Simulasi Ceiling fan Speed Controller yang berbasis Mikrokontroler AT89S51 yaitu dilakukan dengan menggunakan AVO meter, logic probe, dan osiloscope. Pengujian dilakukan pada titik-titik pengukuran yang diperlukan dan disesuaikan dengan alat ukur yang digunakan. Proses pengujian terdiri atas pengujian mikrokontroler, pengujian rangkaian sensor, pengujian driver output, pengujian rangkaian sensor, dan pengujian perangkat lunak dengan single step simulasi, yaitu sebagai berikut:

\section{Pengujian Mikrokontroler}

Pengujian mikrokotroller dilakukan melalui tahapan menyiapkan alat kemudian merangkainya, melakukan pemeriksaan kebenaran pemberian VCC dan ground pada mikrokontroller AT89S51, pemberian program serta melakukan pengujian pada $\mathrm{I} / \mathrm{O}$ Mikrokontroler AT89S51 yang terakhir yaitu mencatat hasil pengujian.

\section{Pengujian Rangkaian Sensor}

Pengujian rangkaian sensor adalah menyiapkan alat kemudian merangkainya, kemudian memasukan tegangan pada sensor kemudian menguji menggunakan fototransistor sebagai receiver, yang terakhir yaitu mencatat hasil dari pengujian

\section{Pengujian Rangkaian IC UDN}

Pengujian rangkaian IC UDN 2981 yaitu menyiapkan alat dan merangkainya,lalu memberikan power supply pada rangkaian kemudian mengujinya dengan menghubungkan rangkaian IC UDN 2981 dengan AVO meter, yang terakhir ,mencatat hasil pengujian

\section{Pengujian Rangkaian Reset}

Pengujian rangkaian reset diawali dengan menyiapkan alat dan bahan kemudian merangkainya, memberikan tegangan pada reset kemudian mengujinya menggunakan logic probe, yang terakhir mencatat hasil pengujian.

\section{Pengujian Perangkat Lunak}

Pengujian ini dilakukan dalam simulasi dengan pembuatan single step program yang disimpan pada mikrokontroller dan dieksekusi secara setahap demi setahap pada tiap instruksinya.

\begin{tabular}{|c|c|c|}
\hline \multicolumn{3}{|c|}{;Contoh listing program } \\
\hline \multirow[t]{2}{*}{; label } & ; opcode & ;operand \\
\hline & Org & $\mathrm{OOh}$ \\
\hline \multirow[t]{3}{*}{ Start: } & mov & $\mathrm{A}_{\alpha}=11111101 \mathrm{~b}$ \\
\hline & Mov & Ro，\#7 \\
\hline & Mov & $\mathrm{p} 0, \mathrm{~A}$ \\
\hline \multirow[t]{5}{*}{ Kiri: } & call & delay \\
\hline & RL & $\mathrm{A}$ \\
\hline & Dec & Ro \\
\hline & CJNE & $\mathrm{RO}_{\text {a }}=0$, Kiri \\
\hline & Sjmp & Start \\
\hline Delay: & mov & R1，\#255 \\
\hline Del1: & mov & $\mathrm{R} 2$ ，\#255 \\
\hline \multirow[t]{4}{*}{ De12: } & Djnz & R2, De12 \\
\hline & Djnz & $\mathrm{R} 1, \mathrm{De} 11$ \\
\hline & Ret & \\
\hline & End & \\
\hline
\end{tabular}

Gambar 5. Listing Program

Hasil pengujian yang diperoleh menunjukkan bahwa setiap bagian dari simulasi ini telah dapat bekerja dengan baik dalam mengendalikan kecepatan putar ceiling fan seperti ditunjukkan pada Tabel 1.

Pada pengujian bagian input berupa fototransistor sebagai sensor terukur tegangan saat high pada rentang 4,7 V sampai $5 \mathrm{~V}$ dan pada saat low pada nilai 0 $\mathrm{V}$ sampai $0,8 \mathrm{~V}$.

Pada pengujian reset yang terdiri atas komponen resistor dan kapasitor terukur tegangan saat high pada kisaran 4,8 V sampai $5 \mathrm{~V}$ dan saat low pada rentang $0 \mathrm{~V}$ sampai $1,3 \mathrm{~V}$.

\section{b) Analisa}

Dalam proses pengujian simulasi ini yang dilakukan dan membandingkan hasil pengujian yang dilakukan maka dapat dianalis pada rangkaian mikrokontroler 
dapat bekerja dengan baik karena pada setiap port yang di berikan logika 1 (high) pada program,maka mengasilkan logika high saat pengukuran.

Pada rangkaian sensor dengan menggunakan fototransistor sebagai receiver sensor berfungsi sebagai saklar on-off biasa. Dimana bila sensor menangkap cahaya maka sensor akan bekerja atau sensor memberikan logikahigh ke Mikrokontroler AT89S51, sedangkan jika sensor tidak menangkap cahaya maka sensor akan tidak bekerja atau memberikan logika low ke Mikrokontroler.

Pada rangkaian IC UDN pengukuran kurang presisi karena perbedaaan tegangan input yang di berikan yaitu sebesar 12 volt. Pada rangkaian reset hasil pengujian rangkaian reset didapat tegangan sebesar 4,5 Volt. Hal tersebut mungkin disebabkan oleh kesalahan dalam pembacaan ataupun alat ukur yang kurang presisi dan nilai toleransi dari resitor yang digunakan. Walaupun hasil yang didapat sedikit berbeda, tetapi tegangan 4,5 volt pada kaki reset sudah menyebabkan kaki ini berlogika 1(high) pada saat saklar tersebut ditekan. Sehingga dapat dikatakan bahwa rangkaian reset sudah berfungsi dengan baik.

Demikian pula saat pengujian perangkat lunak dengan simulasi single step program terhadap mikrokontroller dalam mengeksekusi setiap instruksi telah menunjukkan program berjalan dengan baik dan normal.

Tabel 1. Hasil Pengujian

\begin{tabular}{llllll}
\hline & Pengujian & Kondisi & $\begin{array}{l}\text { Tegangan } \\
\text { High }\end{array}$ & $\begin{array}{l}\text { Tegangan } \\
\text { Low }\end{array}$ & Keterangan \\
\hline $\mathbf{1}$ & Mikrokontroller & Baik & $4,9 \mathrm{~V}$ & $0,9 \mathrm{~V}$ & Normal \\
\hline $\mathbf{2}$ & Sensor & Baik & $4,7 \mathrm{~V}$ & $0,8 \mathrm{~V}$ & Normal \\
\hline $\mathbf{3}$ & Reset & Baik & $4,8 \mathrm{~V}$ & $1,3 \mathrm{~V}$ & Normal \\
\hline $\mathbf{4}$ & Driver Motor & Baik & $4,8 \mathrm{~V}$ & $1,3 \mathrm{~V}$ & Normal \\
\hline
\end{tabular}

Sumber : Suputra, 2018

Pada Tabel 1 ditunjukkan bahwa hasil pengujian pada setiap bagian simulasi yaitu rangkaian mikrokontroller, rangkaian sensor, rangkaian reset, dan rangkaian driver motor yang dujikan telah memberikan kondisi baik dan bekerja dengan normal. Rangkaian ini telah mampu mengkondisikan kerja dari perputaran ceiling fan sesuai yang diinginkan.

Gambar 6 menunjukkan sistem Gambar mikrokontroller Arduino dalam mengendalikan kecepatan putar ceiling fan yang telah teruji mampu bekerja sesuai harapan yang diinginkan. Rangkaian ini sudah terdiri atas rangkaian Kristal untuk pembangkit frekwensi (pewaktuan) dan rangkaian reset.

Rangkaian mikrokontroller tersebut kemudian dihubungkan dengan rangkaian input output yang memberikan sinyal input dari sensor berdasarkan sinyal yang ditangkap oleh fototransistor dan mengirimkan sinyal output kepada driver motor sesuai kondisi saat itu.

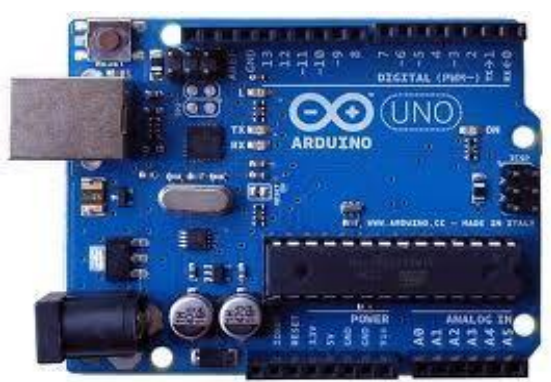

Gambar 6. Arduino

Gambar 7 berikut ini menunjukkan hubungan antara arduino dengan bagian input dan output. 


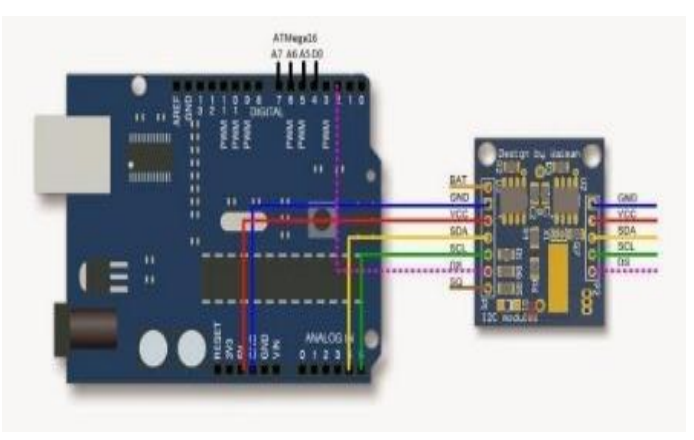

Gambar 7. Rangkaian Input Output

\section{KESIMPULAN DAN SARAN}

\subsection{Kesimpulan}

Berdasarkan uraian pada artikel ini dapat disimpulkan:

1. Simulasi ini dapat bekerja untuk mengendalikan kecepatan putar ceiling fan secara otomatis melalui aplikasi antarmuka.

2. Rangkaian sensor disini yaitu sensor fototransistor, aktif apabila cahaya yang ditangkap terpotong oleh benda, maka logika output dari sensor akan berlogika 1 maka mikro akan memproses data dari sensor penerima.

\subsection{Saran/Rekomendasi}

Berdasarkan penelitian yang telah dilakukan pada sistem sirkulasi dan pencahayaan di laboratorium, maka diperoleh saran untuk penelitian lebih lanjut antara lain:

1. Perlunya ditambahkan fitur untuk mengendalikan kinerja sistem kendali dari jarak jauh seperti menggunakan smartphone android.
2. Diharapkan menggunakan sumber listrik yang lebih stabil agar dapat mengatasi kendala yang disebabkan arus listrik yang kurang stabil.

\section{DAFTAR PUSTAKA}

Andrianto, H. (2013). Pemrograman Mikrokontroler AVR Atmega16 Menggunakan Bahasa C (Code VisionAVR).Bandung: Informatika

Bishop, O. (2004). Dasar-Dasar Elektronika. Jakarta: Erlangga

Budiharto, W. (2008). Panduan Praktikum Mikrokontroler AVR Atmega16. Jakarta: Elex Media Komputindo.

Brindley, K. (2005). Starting Electronics Construction. Loughborough : Copublications

Chandra, B. (2005). Pengantar Kesehatan Lingkungan. Jakarta: Buku Kedokteran EGC

Herjanto, E. (2009). Manajemen Operasi Edisi Tiga. Jakarta: Grasindo.

Kadir, A. (2013). Panduan Praktis Mempelajari Aplikasi Mikrokontroler dan Pemogramannya Menggunakan Arduino. Yogyakarta: Andi

Suputra Widharma, dkk (2018). Simulasi Pengaturan Suhu Ruangan Berbasis Mikrokontroller. Jurnal Logic Vol. 3 No. 1.

https://rezutopia.wordpress.com/2009/03/2 7/mikrokontroler-at89s51/

https://rezutopia.wordpress.com/2009/03/2 7/mikrokontroler-at89s51/

https://funelektro.blogspot.com/2016/06/pengerti an-macam-fungsi- mikrokontroler.html 